\title{
A (semi)formação na Educação Ambiental Universitária: tensionamentos a partir de um estudo empírico sob a ótica da Teoria Crítica
}

\author{
(Semi)formation in University Environmental Education - Critical Theory Tensions in \\ an empirical study
}

\section{La (semi)formación en la Educación Ambiental Universitaria - tensiones a partir de un estudio empírico bajo la perspectiva de la Teoría Crítica}

\author{
Daniela Cássia Sudan ${ }^{1}$ \\ Vânia Gomes Zuin²
}

\begin{abstract}
Resumo
A formação socioambiental, na vertente crítica de Educação Ambiental, aponta para reflexões e ações emancipatórias, em âmbito individual e coletivo, na busca por transformar realidades degradantes da vida em todas as suas formas e sentidos. No entanto, os processos de ensino têm conduzido à semiformação, na atualidade, numa sociedade que coloca inúmeros obstáculos para a concretização da emancipação, na perspectiva da Teoria Crítica. Diante disso, objetivamos discutir, neste artigo, dados derivados de um doutorado sobre um Projeto Universitário de Educação Ambiental de cunho emancipatório, desenvolvido em uma instituição Pública de Educação Superior/IES do Estado de São Paulo/Brasil. Buscamos responder a questão: quais são os sentidos de pesquisaação-participante conferidos pelo grupo coordenador do projeto e como isso reverbera numa perspectiva crítica e emancipatória de formação em EA na IES de interesse? A orientação metodológica desta investigação pautou-se em pesquisa participante e na análise textual discursiva. Dentre os resultados identificam-se leituras diferenciadas do projeto da IES pautado na pesquisa-ação-participante, em que o aprender-fazendo se revela com uma práxis em relação com ações transformadoras, educação popular e reflexão crítica, ao mesmo tempo em que oscila, no referido projeto, um ativismo pragmático. De forma geral, a educação ambiental em capilaridade apontou para a potencialização da autonomia e da liberdade na instituição. Fica o desafio de manter e aprofundar reflexões e ações críticas, como resistência à semiformação nos processos de educação ambiental em universidades.
\end{abstract}

Palavras-chave: Educação Ambiental. Universidade. Teoria Crítica. Semiformação. Pesquisa-participante.

\begin{abstract}
Socioenvironmental formation, considering the critical Environmental Education (EE) perspective, points to reflections and emancipatory actions in the individual and collective scopes, seeking to transform degrading realities of life in all its forms and meanings. However, teaching processes have led to semiformation nowadays, in a society that poses numerous obstacles to the realization of emancipation, as understood by Critical Theory. Therefore, we aimed at discussing some data derived from a $\mathrm{PhD}$ thesis taking into account the Project of Environmental Education in the scope of an emancipatory university, developed in a Public Institution of Higher Education / IES of the State of São Paulo / Brazil. We seek to answer the question: What are the meanings of participatory action-research conferred by the project's coordinating group and how does this reverberate in a critical and emancipatory perspective of EE at the HEI of interest? The methodological orientation of this investigation was based on participant research and discursive textual analysis. Among the results we identify different understanding of the HEI project based on participatory action research, where "learning-by-doing" reveals itself with a praxis in relation to transformative actions, popular education and critical reflection, while oscillates a pragmatic activism in the project. In general, EE in capillarity pointed to the empowerment of autonomy and freedom in the institution. The challenge is to maintain and deepen critical reflections and actions, such as resistance to the semiformation in environmental education processes in universities.
\end{abstract}

${ }^{1}$ Doutora pelo Programa de Pós-Graduação em Educação - PPGE, Universidade Federal de São Carlos - SP, Brasil. Educadora do Departamento de Educação, Informação e Comunicação (DEDIC), da Universidade de São Paulo (USP), no campus de Ribeirão Preto - SP. danisudan@usp.br

2 Pós-doutora em Química pela Universidade de São Paulo (2004) e pelo Centro de Pesquisas Ambientais -

Helmholtz-Zentrum für Umweltforschung / UFZ - Alemanha (2005), Docente do Departamento de Química, Universidade Federal de São Carlos (UFSCar). Docente do Programa de Pós-Graduação em Educação - PPGE. Universidade Federal de São Carlos, Centro de Ciências Exatas e de Tecnologia, Departamento de Química. vaniaz@ufscar.br 
Keywords: Environmental Education. University. Critical Theory. Semi-formation. Participatory research.

\section{Resumen}

La formación socioambiental, en la vertiente crítica de Educación Ambiental (EA), apunta a reflexiones y acciones emancipatorias en ámbito individual y colectivo, buscando transformar realidades degradantes de la vida en todas sus formas y sentidos. Sin embargo, bajo la perspectiva de la Teoría Crítica, en una sociedad que coloca innumerables obstáculos para la concretización de la emancipación, los procesos de enseñanza han llevado a la semiformación en la sociedad actual. Ante eso, el objetivo de este artículo es discutir datos obtenidos de un estudio de doctorado relativo a un Proyecto Universitario de Educación Ambiental, de carácter emancipatorio, desarrollado en una Institución Pública de Educación Superior (IES) del Estado de São Paulo/Brasil. Intentaremos responder a la cuestión: cuáles son los sentidos de la investigación-acción-participante otorgados por el grupo coordinador del proyecto y de qué manera eso se reverbera en una perspectiva crítica y emancipadora de formación en EA en la IES de interés. La orientación metodológica de este estudio. La orientación metodológica de este estudio se pautó en investigación participante y en análisis textual discursivo. Entre los resultados, fueron identificadas interpretaciones diferentes para el concepto de investigación-acción-participante, donde el "aprender haciendo" se revela como una praxis en la relación con acciones transformadoras, educación popular y reflexión crítica, al mismo tiempo en que se nota, en el referido proyecto, oscilación de una visión de activismo pragmático. De manera general, la educación ambiental en capilaridad estudiada apuntó para el potencial de la autonomía y de la libertad en la institución. El desafío consiste en mantener y profundizar reflexiones y acciones críticas, como forma de resistencia a la semiformación en los procesos de educación ambiental en universidades.

Palabras clave: Educación ambiental. Universidad. Teoría Crítica. Semiformación. Investigación participante

\section{Introdução}

Diante do reconhecimento de uma crise civilizatória, a Educação Ambiental (EA) coloca em pauta a necessidade da inclusão das questões ambientais nos processos formativos desde a segunda metade do século XX. A vertente crítica da Educação Ambiental Brasileira e Latino Americana anuncia que essa formação não pode prescindir da análise das relações sociais como mediadoras da construção histórica, econômica, política e cultural da interação ser humano-natureza, tendo como sul $^{3}$ a construção de sociedades sustentáveis. E aponta para reflexões e ações emancipatórias em âmbito individual e coletivo, na busca por transformar realidades degradantes da vida em todas as suas formas e sentidos.

A perspectiva Teórico-Crítica da Escola de Frankfurt ${ }^{4}$ entende que a formação tem se transformado em semiformação numa sociedade que coloca inúmeros obstáculos para a concretização individual e coletiva da emancipação. Nesse sentido, vários pesquisadores e pesquisadoras têm publicado reflexões socioambientais teórico-críticas, trazendo contribuições conceituais sobre a tensão entre economia e ecologia, participação, dialogicidade, pedagogia crítica, ética, emancipação, empoderamento e outras para se repensar os slogans e chavões no campo da sustentabilidade, desenvolvimento sustentável e Educação Ambiental numa perspectiva dialética (TASSARA; ARDANS, 2006; LOUREIRO, 2007; GOERGEN, 2010; ZERBINI, 2011; ZUIN, A.; ZUIN, V., 2012; VIZEU; MENEGHETTI; SEIFERT, 2012; TASSARA, E.; TASSARA, H.; ARDANS, 2013; GOERGEN, 2014; ZUIN, V.; 2015; SUDAN; ZUIN, 2018a, 2018b; SOUZA; LOGAREZZI, 2018; dentre outros).

Nesse bojo, nos inquieta compreender como a busca pela emancipação se efetiva nos processos formativos em EA, diante de inúmeros obstáculos desafiadores. Apresentamos, neste

\footnotetext{
${ }^{3}$ Porque o Sul também é referência de horizonte, suporte e modelo de buscas.

${ }^{4}$ A Teoria Crítica foi desenvolvida pelo Instituto de Pesquisa Social de Frankfurt, na Alemanha, no início do século XX. Seus principais intelectuais, à época, - Adorno, Horkheimer, Marcuse e Benjamin - apresentam uma análise crítica ao capitalismo, articulando referenciais marxistas com aqueles da psicanálise, filosofia e sociologia. Asseveram que as relações sociais são afetadas pelas condições da produção econômica e material, sempre em interação com dimensões da subjetividade e da cultura.
} 
artigo, um recorte dos dados de uma pesquisa de doutorado (SUDAN, 2017) sobre um projeto universitário de Educação Ambiental que assumiu o desafio de promover um processo de EA crítico e emancipatório, numa instituição de Educação Superior (IES) Pública do Estado de São Paulo.

Tal projeto de formação teve como objetivo colaborar na formação socioambiental da comunidade universitária, numa perspectiva emancipatória, rumo à construção de uma universidade sustentável (PLANO POLÍTICO PEDAGÓGICO DO PROJETO UNIVERSITÁRIO, PPP, 20135). Os eixos político-pedagógicos de formação continham repertórios conceitual (conteúdos para estudos e aprofundamentos), situacional (na execução de um diagnóstico socioambiental na universidade) e operacional (elaboração e execução de práticas educativas e de gestão ambiental nos campus envolvidos), adaptados de uma política pública brasileira com referenciais de uma perspectiva crítica de EA (FERRARO JUNIOR; SORRENTINO, 2005; BRASIL, 2006).

Explicita-se, em seu plano político-pedagógico, uma tendência em problematizar algumas questões socioambientais, como a insustentabilidade da sociedade atual, indústria cultural, história e fundamentos da EA, políticas públicas, gestão ambiental, educação e emancipação, dentre outros, indicando bases de uma EA Crítica. Os temas da EA, educomunicação e políticas públicas são apresentados como transversais a todos os módulos e práticas (PPP, 2013).

Na busca por envolver o maior número de participantes e ampliar a EA na instituição, desenvolveu-se uma arquitetura de capilaridade (BRASIL, 2006). A proposta envolve a atuação em rede de coletivos com um propósito educador. Esse formato carrega um imperativo da ação, entendendo que esta propicia algo diferente ao servidor e à sua localidade durante sua formação socioambiental. Com uma matriz teórico-metodológica de pesquisa-ação-participante, os envolvidos no projeto chegam ao processo em momentos sequenciais de formação, compondo os coletivos PAP 1, 2, 3 e $4^{6}$.

$\mathrm{Na}$ arquitetura de capilaridade, a instância proponente do projeto atua como PAP1, na articulação das equipes e das ações em rede, assim como na coordenação e execução da formação dos PAP2 (servidores experientes ${ }^{7}$ na área). Num momento seguinte, os PAP2 desenvolvem práticas junto a outros colegas de trabalho do seu campus de origem - os PAP3. Por fim, os PAP3 promovem uma série de ações educativas junto a servidores de sua localidade, os PAP4. Cabe ressaltar que a carga horária de formação socioambiental para cada um desses grupos foi decrescente $-180 \mathrm{~h}$ para os PAP1 (com reuniões de planejamento e avaliação, supervisão de equipe de bolsistas e estagiários; formação e tutoria aos PAP2.), 130h para os PAP2 e 40h para os PAP3 (realizando, esses dois grupos, atividades presenciais e práticas monitoradas). Os PAP4 participaram de oficinas teórico-práticas com duração entre 2 a $8 \mathrm{~h}$.

O total de participantes desse processo foi de 2.500 pessoas, no período de março de 2013 a outubro de 2015, em sete campus universitários. Os 92 PAP2 desenvolveram 31 cursos $(40 \mathrm{~h})$ sobre socioambiente para 533 PAP3. Os PAP3 promoveram 127 ações de EA de curta duração, com a participação de 1.853 PAP4. Também se anunciam como resultados do projeto um website, a montagem de uma plataforma virtual e um livro (com a participação voluntária dos PAP1, 2 e 3), onde são relatados resultados quanti-qualitativos sob diferentes olhares dos

\footnotetext{
${ }^{5}$ Não especificado nas referências finais do artigo para a manutenção do anonimato dos participantes.

${ }^{6}$ Cabe ressaltar que a EA em capilaridade não se define por formação de multiplicadores, termo comumente difundido no senso comum, que, em geral, supõe a reprodução automática e em cadeia das informações recebidas num curso. Aqui, trata-se de uma rede de coletivos que possuem o desafio de conceber e promover práticas criativas, críticas e reflexivas junto a diversos públicos.

${ }^{7}$ Que já atuaram em gestão ambiental e/ou foram membros de instâncias (comissões, grupos de estudo etc.) ambientais na universidade.
} 
participantes (RELATÓRIO DO PROJETO, 2016) ${ }^{8}$. Dados, estes, que expõem um projeto de grande envergadura e aparentemente inovador em universidades, mesmo em âmbito internacional (SUDAN; ZUIN, 2018a).

Tal perspectiva metodológica da pesquisa-ação-participante, traduzida pelos seus coordenadores e coordenadoras como pessoas que aprendem participando, enfatiza a relevância da participação e da prática em capilaridade como propiciadoras de aprendizagens e de uma formação socioambiental crítica. Mas o que se aprende, como se aprende e que relação é essa de participar e aprender? são questões colocadas em xeque pelo próprio grupo coordenador em seus momentos reflexivos, diante de barreiras que encontram no processo de desenvolvimento do referido projeto na instituição.

Buscamos, neste trabalho, portanto, focar luzes nos aspectos mais desafiadores do projeto quando, ao tentar lidar com seus dilemas da prática e contradições, explicita tensões entre o vivido e a almejada formação emancipatória com reflexões relevantes para o campo da Educação Ambiental. Objetivamos responder à seguinte questão: Quais são os sentidos de pesquisa-ação-participante conferidos pelo grupo coordenador do projeto e como isso reverbera numa perspectiva crítica e emancipatória de formação em EA na IES de interesse?

Para atingir o objetivo pretendido, é pertinente introduzirmos um breve histórico da Educação Ambiental e da formação socioambiental em universidades brasileiras, aspectos estes que consideramos importantes para a compreensão do projeto investigado (que carrega influências acumuladas ao longo dessa história) e para a reflexão sobre a problemática em foco. Além disso, apresentamos o referencial teórico-metodológico da pesquisa de doutorado, que dá bases para a análise e discussão em torno do corpus de dados. Ao final, tecemos algumas considerações sobre a formação socioambiental em universidades, numa perspectiva teóricocritica.

\section{EA no ensino superior brasileiro}

A EA no Ensino Superior brasileiro é mais antiga do que sua institucionalização, com uma série de projetos, ações, eventos e documentos protagonizados por diferentes atores e universidades, sob referenciais teóricos diferenciados, como descrito na literatura (CARVALHO; TOMAZELLO; OLIVEIRA, 2009; OLIVEIRA; FREITAS, 2006). Dentre muitas das iniciativas, destacamos os seminários sobre Universidade, Educação e Meio Ambiente, em âmbito federal, nas décadas de 1980 e 1990 (BACCI; SILVA; SORRENTINO, 2015). Nesse âmbito, também há importantes documentos internacionais, elaborados na década de 1990, que abordam a relação das universidades com a Educação Ambiental, como a diretriz 19 do Plano de Ação, do Tratado de Educação Ambiental para Sociedades Sustentáveis e Responsabilidade Global (1992), e o Capítulo 36 da Agenda $21^{9}$ (1995).

Em conexão com as questões de meio ambiente, gestão e educação ambiental na universidade, destacamos, também, a atuação da Rede Aces - Ambientalização Curricular do Ensino Superior - como a deflagradora do termo ambientalização universitária no Brasil. Formada por onze universidades (dentre elas, cinco latino-americanas, sendo três IES públicas brasileiras), essa rede internacional e interinstitucional atuou no período de 2000 a 2004, sob o fomento do Programa Alfa, da União Europeia (CARVALHO; SILVA, 2014).

Também, ressaltamos a criação da Rede Universitária de Programas de Educação Ambiental para Sociedades Sustentáveis (RUPEA), em 2001, com uma perspectiva convergente para a EA crítica e a construção de sociedades sustentáveis (FERRARO JR., 2014). Juntamente às ações de formação, essa rede coordenou um Mapeamento da Educação

\footnotetext{
${ }^{8}$ Não especificado nas referencias finais do artigo para a manutenção do anonimato dos participantes.

${ }^{9}$ Referente à educação, promoção do ensino, da conscientização e do treinamento
} 
Ambiental em Instituições Brasileiras de Educação Superior, do qual participaram 22 instituições (públicas e privadas), de diversos estados brasileiros (OLIVEIRA et al., 2007). Os dados levantados apontam demandas (ainda hoje prementes) relacionadas à: criação de instâncias universitárias para promover a institucionalização da EA na Educação Superior, fomento à cooperação intra e interinstitucional; investimentos na capacitação de gestores e na formação de educadores ambientais e especialistas (CARVALHO; FARIAS, 2011).

No entanto, após décadas de implementação da EA nas universidades, Sorrentino e Biasoli (2014, p. 39) apontam que esse tema ainda é marginal nas IES, com ações descontinuadas, como "vaga-lumes que acendem e apagam". Brandli et al. (2015), quando esboçam um panorama da ambientalização nas universidades brasileiras, também identificam iniciativas pontuais, sem uma articulação institucional regulada e orientada por uma política.

Em âmbito internacional, Disterheft et al. (2015) reconhecem avanços mundiais com relação à sustentabilidade, presentes nas pautas universitárias, nas últimas décadas. Mesmo assim, apontam que ainda não se observam mudanças efetivas na gestão universitária, associadas a uma mudança cultural na organização. Em geral, as ações ficam restritas ao voluntariado, num formato limitado de participação individual e coletiva, sem acesso à tomada de decisões.

Embora Zuin (2010, p. 235) destaque a relevância das iniciativas existentes, mesmo que pontuais, pois podem dar base a um processo mais intensificado de participação da comunidade universitária, também assevera que a ambientalização universitária deve enfrentar o desafio da racionalidade instrumental, valorizar a hibridação de saberes e materializar novos trajetos. Da mesma forma, Sjötröm, Eilks e Zuin (2016), resgatam o conceito de Bildung, apontando que a ambientalização implica em construir uma nova visão ecorreflexiva de mundo e cosmologia, para se repensar aspectos da educação, do ensino e da sustentabilidade nos currículos, o que exige conhecimento histórico, reflexões filosóficas, éticas e morais, sobre os quais trazemos alguns apontamentos, a partir de referências da Teoria Crítica.

\section{A questão da formação problematizada pela Teoria Crítica}

O conceito de formação, segundo um dos principais filósofos teórico-críticos, Adorno (2010), ascendeu com a burguesia, que, quando chegou ao poder político na Europa (dos séculos XVII e XVIII) apresentava-se mais desenvolvida econômica e culturalmente que no feudalismo. No entanto, essa jovem burguesia não desenvolveu o potencial libertário e a formação cultural que defendia. Ao contrário, promoveu a dominação sobre outras classes sociais com base na repressão social, no totalitarismo e na razão instrumental.

Somado a isso, foi desenvolvida e fortalecida, no século XX, no bojo do sistema capitalista, a indústria cultural, que viria a impactar profundamente a formação da sociedade em geral. Para a Teoria Crítica, essa indústria da cultura é assim chamada porque é parceira e está a serviço de setores industriais poderosos, como o do aço, do petróleo, da eletricidade e da química, fomentando a padronização, produção e consumo em série de mercadorias (ADORNO; HORKHEIMER, 1985). Usando das várias tecnologias disponíveis no início do século XX (rádio, televisão, cinema e música) como instrumentos de dominação, a indústria cultural apresentava uma sucessão acelerada de coisas aparentemente novas, mas que "têm a imitação como algo de absoluto", compondo um sistema que funciona "no esquematismo da produção" (ADORNO; HORKHEIMER, 1985, p. 123). Além disso, tais tecnologias midiáticas propiciavam, e continuam propiciando um entretenimento aos trabalhadores e trabalhadoras, como uma forma de anestésico para o pensamento crítico.

Diante desse cenário, "a cultura se subsume à lógica de produção e reprodução do capital” (ZUIN, V.; ZUIN, A. 2016, p.761), com a mercantilização dos bens culturais e o 
empobrecimento da experiência formativa, com o prejuízo da memória e da analise críticoreflexiva, tão importantes na formação cultural de um cidadão.

De modo semelhante, um suposto conceito de sustentabilidade também passou a ser propagado pela indústria cultural hodierna (ZUIN, V.; ZUIN, A., 2012), que, valendo-se de um slogan verde, promove a ideia distorcida do desenvolvimento sustentável. Assim, a indústria cultural nega as premissas da conservação ambiental e da emancipação, à medida que estimula o consumo desenfreado e expõe uma reconciliação forçada entre cultura e natureza.

Neste âmbito, o termo "sustentabilidade" pode se tornar contraditório "por se apresentar como uma verdade salvadora, como um mito salvador ante o apocalipse eminente", ao mesmo tempo em que é usado por agentes que promovem sistematicamente a degradação ambiental (VIZEU; MENEGHETTI; SEIFERT, 2012, p. 582). A racionalidade predominante sobre o conceito de desenvolvimento sustentável, portanto, ampara-se em um pragmatismo utilitarista, apresentando a sustentabilidade meramente como um discurso, necessário e útil, na medida em que legitima as práticas de corporações e grupos que servem aos interesses das elites econômicas.

A fetichização do consumo e o culto à mercadoria, potencializados pela indústria cultural, representam a liquidação da cultura e estabelecem uma crise de formação cultural que resulta num problema de semiformação ${ }^{10} \mathrm{em}$ toda a sociedade (ADORNO, 2010). A semiformação ${ }^{11}$ serve a um duplo propósito: tanto para promover a adaptação do ser humano como animal a ser dominado, como para, com isso, manter a ordem instituída. Assim, numa sociedade capitalista, a formação cultural e o ócio são negados aos trabalhadores, ficando com a elite dominante o controle e o acesso a eles, num esquema articulado de minimização de crítica e resistência ao sistema.

Zuin, V. e Zuin, A. (2017) discutem a atualidade do conceito de semiformação para repensarmos a educação contemporânea e o potencial presente de renascimento da Bildung, a partir de uma análise das atuais mediações históricas da indústria cultural, como a cultura digital e a internet das coisas. Respaldados por diversas obras, como a de Türcke (2010), ressalvam que é na atualidade midiática que se desenvolve a distração concentrada em caráter de vício, principalmente pelo uso dos aparelhos celulares individuais, que bombardeiam choques audiovisuais ininterruptos, configurando uma nova ontologia, "a de que ser significa ser percebido por meio da compulsão, para emitir a própria imagem e comentários, sobretudo por meio do uso incessante das redes sociais" (ZUIN, V.; ZUIN, A., 2017, p. 427).

A domesticação e ajustamento das pessoas a uma dada realidade, sem questionamentos ou resistências, têm potencial destrutivo na formação humana, pois leva ao conformismo, à perda da desconfiança perante o que é dado como verdade. Exclui a reflexividade, estimula o pensamento estereotipado, revelando "racionalizações justificadoras de atitudes autoritárias e preconceituosas" (ZUIN, V.; ZUIN, A. 2017, p. 762). Assim, pode ocorrer adesão cega de muitas pessoas a coletivos que, de forma irrefletida, podem promover barbáries (ADORNO, 2010). Nesse sentido, a barbárie não é algo do passado e raro acontecimento de algumas nações ou povos, mas, sim, algo já manifesto ou que pode vir a renascer em diversos níveis, bem ao nosso lado, com o suporte de indivíduos e coletivos alienados.

Como Gruschka (2014) enfatiza, muitos dos sintomas da frieza, fomentados no capitalismo, confirmam que a recaída no princípio de Auschwitz permanece possível, que ele pode ocorrer diariamente, das mais variadas formas. Daí a função da Teoria Crítica em revelar

\footnotetext{
${ }^{10}$ Halbbildung - Halb = semi, bildung = formação humana; como se a formação humana ficasse obstacularizada socialmente.

${ }^{11}$ Para Adorno, semiformação e "a não cultura são conceitos diferentes, sendo o segundo "mera ingenuidade e simples ignorância”, que carrega qualidades (ceticismo, ironia etc.) de pessoas não inteiramente domesticadas, que ainda podem desenvolver consciência crítica (algo fora do alcance do semiformado) (ADORNO, 2010, p.21).
} 
as raízes desse processo em movimento, colaborando para expor possibilidades para transformação (ADORNO, 2010).

O caminho da formação cultural tradicional (embora fundamental nos processos de formação), segundo Adorno, pode conduzir ao contrário da emancipação, sendo a autorreflexão crítica sobre a semiformação "a única possibilidade de sobrevivência que resta à cultura" (ADORNO, 2010, p. 39). Logo, a Educação e seus intelectuais têm um importante papel a desempenhar na formação de uma consciência crítica sobre a realidade cultural, econômica, social e histórica. A importância da Educação também está no processo de questionar a identificação cega com o coletivo, em promover esclarecimento sobre as desigualdades, barbáries e sobre a frieza legitimadas no capitalismo.

Para Goergen (2010, p. 227), a universidade também deve incorporar esse legado, pois é o locus onde "deve predominar o princípio da eterna busca, o combate à burocracia; e o estímulo ao desenvolvimento de cada um, na autonomia". Deve se comprometer com uma formação que desenvolva uma consciência crítico-transgressora, para enfrentar a manipulação e pensar a construção do futuro. Deve enfrentar o desafio de "recuperar o potencial perturbador da razão" (GOERGEN, 2014, p. 570).

Sigamos, investigando como isso se expressa no projeto de formação socioambiental universitário.

\section{Percurso metodológico}

A Teoria Crítica também nos fornece um arcabouço reflexivo sobre o método, que nos instiga a ampliar o olhar sobre o objeto de estudo (SUDAN, 2017), alertando-nos para não nos conformarmos com a superficialidade e coparticipação na pesquisa, mas ir à teoria para ir mais longe (PUCCI, 2000); resistirmos às sistematizações que funcionam como "camisa-de-força para cobrir a realidade" (PUCCI, 1998, p. 1); considerarmos as contradições do processo (FARIA; MENEGHETTI, 2011); procurarmos ser profundos/robustos na análise, justificando as categorias escolhidas, mantendo-nos sensíveis a diversos formatos de dados, muitas vezes ignorados por serem difíceis de captar (ADORNO, 1996; GRUSCHKA, 2014).

O método qualitativo para investigar o processo de formação socioambiental na IES de interesse foi estruturado a partir de uma pesquisa participante (BRANDÃO, 1987), caracterizada por uma trajetória compartilhada entre sujeitos e pesquisadora na prática de uma pesquisa que se associa diretamente a uma prática política pela busca de transformação de uma realidade.

Essa tradição de pesquisa ${ }^{12}$, influenciada pelas tradições europeias e norte-americana, tomou contornos específicos na América Latina, entre os anos de 1970 e 1980, devido aos contextos sócio-políticos das ditaduras prevalentes nessa região. Tem uma vinculação histórica junto aos movimentos sociais populares e com os seus projetos de transformação social emancipatória, sob forte influência de autores como Karl Marx, Antônio Gramsci, Paulo Freire e Orlando Fals Borda ${ }^{13}$. Como um dos princípios mais consensuais da pesquisa participante está o de que "toda a ciência social de um modo ou de outro deveria servir à política emancipatória e deveria participar da criação de éticas fundadoras de princípios de justiça social e de fraternidade humana" (BRANDÃO, 2006, p. 24-25).

Assumimos, neste trabalho, a pesquisa-participante e seus pressupostos, levando em conta a implicação da pesquisadora com o desenvolvimento do projeto de Educação Ambiental

\footnotetext{
${ }^{12}$ Que inclui a pesquisa-ação-participante, matriz teórico-metodológica do projeto de EA investigado no projeto de doutorado.

${ }^{13}$ Este autor cunhou o termo PAP - pesquisa-ação-participante, em 1983, como uma metodologia que inclui educação de adultos, pesquisa científica e ação social ou política, tendo como fonte de conhecimento a análise crítica, o diagnóstico de situações e a prática cotidiana (GAJARDO, 1987).
} 
na universidade ${ }^{14}$ e, ao mesmo tempo, da implicação dos participantes do projeto universitário na colaboração com sua pesquisa de doutorado. Nessa condição, todo pesquisador deve atentarse para sua responsabilidade de manter o foco nos objetivos estabelecidos em relação ao estudo, amparado em referenciais teóricos ao revisitar a experiência prática (ROCHA, 2004). Ao mesmo tempo, concordamos com Gondim (2003) que o contexto individual, social, cultural e histórico de qualquer pesquisador sempre estará em jogo no desenvolvimento de sua pesquisa.

A IES envolvida na pesquisa agrega em torno de 120.000 pessoas (estudantes, servidores técnicos e professores) em mais de dez campus universitários do estado de São Paulo/Brasil. O projeto empírico foi desenvolvido no período de 2012-2015, sob a coordenação de um órgão Ambiental da IES pesquisada. Ao todo, o grupo participante da pesquisa ${ }^{15}$ somou 44 pessoas, todas com vínculo com a universidade em foco, de diferentes faculdades e campus, formado por docentes, estudantes da graduação (como bolsistas e estagiários), servidores técnicos da instituição e profissionais contratados temporariamente que compuseram a equipe coordenadora do projeto ${ }^{16}$ (SUDAN, 2017).

Compõem o corpus de dados para análise os documentos elaborados por esse grupo coordenador do projeto universitário ${ }^{17}$; as transcrições de entrevistas por grupo focal (GONDIM, 2003; KIND, 2004) e notas de observação participante da pesquisadora (BRANDÃO, 2006). Foram desenvolvidos dois grupos focais, com participação voluntária dos membros do grupo coordenador do projeto, conduzidos a partir de um roteiro prévio e registrados com gravação em áudio (para posterior transcrição), com a colaboração de uma graduanda. Entendemos como possíveis benefícios da participação no grupo focal, para os participantes, a possibilidade de: aprendizagens em novos campos teóricos; um repensar teórico sobre diversas temáticas, como o da emancipação e formação; oportunizar momentos/ espaços de avaliação e amadurecimento da prática coletiva do projeto em desenvolvimento na universidade.

A análise dos dados foi baseada em premissas da Teoria Crítica da Sociedade e da análise textual discursiva (MORAES, 2003; MORAES; GALIAZZI, 2006). Muitas leituras e releituras foram realizadas pela pesquisadora sobre o corpus, para amadurecer um estranhamento necessário sobre a práxis desse projeto e também reconhecer elementos ocultos, perturbadores ou irritantes, como Pucci (2000) destaca. Na escolha e análise de "elementos irritantes e perigosos que vivem na opacidade desse particular" (op. cit., p. 3), foram buscadas contradições e lampejos ${ }^{18}$ dialéticos emancipatórios.

Moraes (2003) faz uma analogia do processo de analise textual discursiva dos dados a uma tempestade de luz. Um novo texto pode surgir a partir de uma desordem inicial, em movimentos hermenêuticos espirais, atingindo compreensões cada vez mais aprofundadas sobre o que se investiga. Isso pode ser desenvolvido com um compromisso desafiador de leitura critica dos dados em quatro etapas básicas a) unitarização, etapa marcada pela desorganização do texto, separando-o em unidades; b) categorização entre as unidades; c) construção de um metatexto diferenciado do texto original, e por fim, d) constituição de um novo texto, que

\footnotetext{
${ }^{14}$ A pesquisadora é servidora técnica desta instituição desde 2001.

15 Todas as ações de produção de dados, bem como o projeto geral desta pesquisa foram aprovados pelo Comitê de Ética da Universidade, associado ao cadastro do mesmo na Plataforma Brasil, do sistema Nacional de Ética em Pesquisa / SISNEP.

${ }^{16}$ A delimitação dos sujeitos de pesquisa foi realizada diante de uma enormidade de dados, sob a consideração de que o grupo coordenador é o que mais produziu informações no processo e guarda em si maior reflexibilidade, aprofundamento teórico, potencial crítico e registros do processo vivido.

${ }^{17}$ Dentre os documentos, temos dezoito memórias de reuniões e sete transcrições de gravações destas; o plano político pedagógico e relatórios do projeto.

${ }^{18}$ Referendando Moraes (2003) que faz uma analogia do processo analítico a uma tempestade de luz.
} 
expresse resultados criativos e originais não previstos, que possibilite novas compreensões dos dados.

A fase de unitarização demanda, segundo Moraes (2003, p. 195):

Colocar o foco nos detalhes e nas partes componentes, um processo de divisão que toda análise implica. Com essa fragmentação ou desconstrução dos textos, pretendese conseguir perceber os sentidos dos textos em diferentes limites de seus pormenores, ainda que compreendendo que um limite final e absoluto nunca é atingido. É o próprio pesquisador que decide em que medida fragmentará seus textos, podendo daí resultar unidades de análise de maior ou menor amplitude.

Com um papel central na análise textual, a linguagem permite ao pesquisador expor sua própria voz num "movimento da compreensão, de construção e reconstrução das realidades" a partir da voz de outros sujeitos, segundo Moraes e Galiazzi (2006, p. 123). Em seguida, buscouse compreender o contexto em que ocorriam essas unidades elementares no texto geral, num exercício de construção de um metatexto analítico que possibilitasse novas compreensões dos dados.

Uma categorização a priori dos temas centrais do projeto investigado em articulação com a Teoria Crítica foi realizada, com a reunião de elementos relacionados à emancipação e subcategorias de liberdade e autonomia e (semi)formação. Uma categoria (não definida $a$ priori) emergiu após inúmeras leituras dos dados, a que envolve os não docentes. Definidas essas categorias centrais, buscamos localizar unidades elementares em torno delas no corpus de dados ${ }^{19}$.

Optamos por apresentar neste artigo somente uma das categorias centrais da tese $-a$ dialética da formação socioambiental de servidores, que representa um ponto nodal do Projeto PAP e implica visões de como as pessoas se educam e de como isso se expressa na práxis do projeto. Dentro dela, apresentamos duas subcategorias para análise dos dados, quais sejam: i) Formação socioambiental e, ii) Pesquisa-ação-participante como núcleo teórico-metodológico da formação, discutidas na sequência do artigo.

\section{A dialética da formação socioambiental de servidores}

\subsection{Formação Socioambiental}

O termo formação socioambiental aparece 55 vezes no corpus, sendo 33 vezes relacionada ao título do projeto nas memórias das reuniões do grupo coordenador; uma vez indicando a Educação à distância (EAD) como potencializadora da formação; três vezes com referência à infraestrutura do projeto; quatro vezes abordando conteúdos e demandas dos campus; seis vezes associada à definição dos objetivos do projeto e oito vezes indicando seu significado, sua finalidade, conforme excertos priorizados para análise, apresentados a seguir.

Em associação ao termo formação socioambiental, o grupo coordenador do projeto anuncia como: É o nosso objetivo (Ariá20); ela mexe com o social também [ ], com as pessoas, trabalho em grupo; todo mundo que a gente conversa com elas estão preocupadas com o resíduo, e não com a parte social né, daquilo, que aquilo reflete na sociedade (Aguapé); É uma coletividade (Fisális) (Excertos da transcrição, grupo focal, 08 de abril de 2015).

Tais manifestações exprimem, de forma sucinta, alguns jargões de uma formação crítica, como os princípios de trabalho coletivo e da interconexão do social ao ambiental.

\footnotetext{
${ }^{19}$ Localizadas nos arquivos de memórias de reuniões e transcrições de grupo focal , usando palavras-chave com o comando "localizar" do Word/Windows.

${ }^{20}$ Foram usados codinomes de Plantas Alimentícias Não convencionais / PANCs em excertos que expõe falas dos participantes.
} 
Carvalho (1998, 2001), González-Gaudiano (2001), Lima (2002), Ferraro Jr., Sorrentino (2005), Loureiro et al. (2009), Carvalho, Tomazello, Oliveira (2009), Tonso (2010), Layrargues, Lima (2011), dentre outros, asseveram que a consideração das relações sociais como imbrincadas à questão ambiental, torna fundamental o desenvolvimento de uma postura crítica frente à sociedade atual, debruçando-se sobre o funcionamento do sistema econômico hegemônico e suas mazelas.

Como apontado na introdução, o PPP (2013) do projeto anuncia três repertórios políticopedagógicos de formação: conceitual, situacional e operacional/de práticas. Na discussão sobre o repertório conceitual, com os conteúdos fundamentais da formação, o grupo coordenador refletiu sobre o que era esperado de cada PAP, desembocando na discussão de motivar o desejo de mudança na universidade, da importância de conteúdos reflexivos e da necessária democratização da gestão na referida IES (Excertos - Memória de reunião, 27 de maio de 2013). Aspectos, estes, apontados como fundamentais no desenvolvimento de EA crítica, na busca por consolidar e ampliar a democracia no Estado e em nossa sociedade, a qualidade de vida e a preparação para tomadas de decisão de interesse público (LIMA, 2002).

$\mathrm{Na}$ implementação do repertório situacional, o diagnóstico prévio realizado pelos PAP2 resultou em um levantamento de iniciativas pré-existentes nos campus e suas lacunas (problemáticas socioambientais) de gestão ambiental. As repetidas queixas dos servidores nesse âmbito se referiam às soluções técnicas que já possuíam para certos problemas identificados, mas que nunca puderam ser implementadas. Umbu retoma essa questão em uma das reuniões: O conflito maior sempre será a Instituição e como fazer o enfrentamento (Excerto - Memória de reunião, 19 de março de 2014).

A intensa agenda de tarefas do processo de formação também interferiu no processo de desenvolvimento dos diagnósticos pelos PAP2, com "pouco tempo para aprofundar o diagnóstico" (Baru) (Excerto - Memória de reunião, 19 de março de 2014).

O passo seguinte de dissecação de tais questões e lacunas, e porque assim o são dentro da instituição, não foi dado, minimizando o desenvolvimento de uma percepção mais abrangente sobre por que as problemáticas são mantidas e reproduzidas. Com isso, entendemos que o potencial emancipatório do diagnóstico socioambiental da instituição foi minimizado por imperativos de múltiplas ações práticas e seus prazos emergenciais.

Concordando com a importância que um diagnóstico rigoroso da sociedade, com a identificação dos obstáculos colocados à emancipação social, é fundamental para constituir base para uma crítica adequada e, que não é possível desenvolver um diagnóstico aprofundado sem uma análise crítica ao capitalismo (ADORNO; HORKHEIMER, 1985), fica a dúvida se o processo de formação socioambiental atingiu esse ponto crítico com uma abordagem superficial de problemáticas socioambientais.

Dos três breves excertos do corpus que envolvem a palavra "capitalismo", um deles se refere à observação de uma professora que propõe não abordar a ação educativa por essa via (de crítica ao consumo e ao capitalismo), pois um caminho do meio devia ser buscado e falar então qual o meio termo desse pessoal aí, o que eles querem? O utópico? (Hibisco, excerto da transcrição da Reunião do Grupo Coordenador, 30/09/2013).

Em termos de repertório operacional/de práticas nas faculdades e órgãos, o planejamento das intervenções com inspiração em tais lacunas não se efetivou para uma grande parte dos PAP2. Muitos grupos preferiram fazer intervenções sobre outras temáticas ${ }^{21}$. Aí, talvez, esteja a percepção de parte dos PAP sobre a impossibilidade de resolução de certas lacunas na instituição, à qual se ajustaram ou não viam caminhos para transformá-las ou superálas naquele momento. Anos de trabalho numa instituição burocrática e hierarquizada vão

\footnotetext{
${ }^{21}$ Como oficinas de reaproveitamento e reciclagem de papéis junto à laboratórios com resíduos perigosos.
} 
estimulando (e exigindo), como alertam Horkheimer e Adorno (1973), uma adaptação forçada à realidade.

\subsection{Pesquisa-ação-participante como núcleo teórico-metodológico da formação}

Embora o conceito de pesquisa-ação-participante tenha sido um pilar teóricometodológico do projeto de formação, no corpus de dados o seu significado pouco foi discutido. Apareceu quatro vezes, de forma sucinta, conectado aos excertos de: capilaridade; a uma especificação do termo como método do projeto de formação; à tradução de $P A P$ e a pessoas que aprendem participando (termo que foi mais usado pelo grupo coordenador para traduzir o conceito de pesquisa-ação-participante e o projeto em si). Os termos aprender fazendo e pessoas que aprendem participando, também muito utilizados pelo grupo coordenador para explicar os objetivos do projeto, apareceram, respectivamente, dez e doze vezes no corpus de dados.

O significado de aprender fazendo é adotado pelo projeto no sentido de que nos potencializa para o agir; da educação pela práxis. Ao mesmo tempo, é um termo que tem um impacto numa sociedade onde a gente não faz nada, não vê resultado, [...] às vezes o resultado das nossas ações demora uns 10, 15, 20 anos para a gente ver o impacto dele (Pupunha, excerto da transcrição de reunião, 22 de agosto de 2013). E nesse sentido, o fazer em projetos de EA ganha uma dimensão importante: a de animar esse longo processo que é a construção de resultados na educação. Pupunha ressalta, mais uma vez, esse aspecto em sua fala: a gente vê muitos projetos de horta, viveiro, que são singelos, ou mesmo de lixo, que é o mais comum, né? De pegar lixo, tudo, e que faz sucesso, e você fala - poxa, porque faz sucesso? Porque as pessoas põem a mão na terra, as pessoas fazem e elas veem o resultado. (Pupunha, excerto da transcrição de reunião, 22 de agosto de 2013).

O número de ações foi grande no período do projeto. Fez-se muito. Na defesa de que sempre se aprende ao praticar a EA no cotidiano da instituição, o grupo coordenador foi provocado a refletir sobre o que é que se aprende-fazendo. Umbu aponta o que a instituição não aprende fazendo, não aprende com o que ela faz, expressando uma dissociação, uma cisão e incoerência internas. No lugar social legitimado como produtor de conhecimentos, não se internalizam seus próprios resultados:

Umbu: [...] dentro de uma instituição, e essas pessoas que aprendem participando, também são pessoas que estão trabalhando, não é, e estão regidas por todo um sistema de hierarquia, de disciplinamentos. Então, traz um ingrediente novo para essa situação. [...] porque ela não é uma instituição simples, no meu ponto de vista é uma instituição que está doente, ela está esquizofrênica... A própria estrutura dela, não tem uma cabeça, você tem eventualmente uma liderança, geralmente autoritária, [...] ela não consegue criar um corpo consistente do que ela quer, são os arranjos, [...] um dos problemas é que não é uma instituição que aprende fazendo, eu acho até um absurdo teoricamente uma instituição de formação, de conhecimento, mas o conhecimento que é gerado na instituição, não ensina para instituição... então o processo dentro de uma corporação, onde as pessoas estão participando e aprendendo, também estão submetidas a isso e essa mesma instituição, é complexa, é difícil[...] e essas pessoas que aprendem participando estão mais submetidas mais na situação de acatar alguma coisa, do que conseguir deliberar e dar rumos (GRUPO FOCAL 1, 08 de abril de 2015, p.8).

A cegueira da racionalidade instrumental, tratada por Adorno (1985), se faz evidente na universidade que não aprende (como poderia) com o que faz. Reprodutora dessa lógica, a universidade saboreia seus próprios prejuízos da falta de diálogo interno, da fragmentação de saberes, se fecha na competitividade produtivista de mercado e empobrece experiências. Mas brotam e resistem muitas experiências alternativas potenciais, que podem colaborar na 
integração das dimensões cindidas do aprender fazendo. Colocar seus servidores, de diferentes funções, setores e campus, para dialogar e trocar experiências sobre a questão ambiental na instituição representou uma negação do isolamento competitivo, reconhecido por Taioba: [...] se de fato ela olhasse esse processo como a gente vê, e como a gente pensa que ele deva ser, de formação, de transformação, de apropriação, e de criticidade, ele fica subversivo em relação à universidade (Excerto do Grupo Focal 2, 04 de maio de 2015).

Alguns participantes do grupo focal compreendem que o conceito de aprender-fazendo perpassa o conflito (Ariá); a práxis (Pupunha) e aprender sobre a área ambiental que também não é valorizada; de servidor para próprio servidor da instituição (Aguapé) (Excertos do Grupo Focal 1, 08 de abril de 2015).

No entanto, embora possamos constatar que parte do grupo coordenador do projeto PAP estabelece uma relação entre práxis e o aprender fazendo, há que ponderar sobre uma possível contradição no processo. Duarte (2001) aponta que expressões de métodos ativos, como aprender fazendo, learning by doing, aprender a aprender, tem influências e origem, sobretudo, no movimento escolanovista. E tais lemas estão presentes em um importante documento da área educacional: no relatório da comissão internacional da UNESCO, conhecido como Relatório Educação: um tesouro a descobrir (DELORS et al, 2010) ${ }^{22}$.

No citado documento foram destacados quatro pilares da educação para o século XXI: o aprender a conhecer, aprender a fazer, aprender a conviver e aprender a ser. Para Duarte (2001), a partir desses pilares propaga-se que a educação deve preparar os alunos para enfrentarem os processos acelerados de mudança na sociedade, o dinamismo de informações e a provisoriedade dos conhecimentos. Segundo o autor, o aprender a aprender é apresentado "como uma arma na competição por postos de trabalho, na luta contra o desemprego" (DELORS, 2010, p. 36), esvaziado de crítica e distanciado do conceito de práxis, por tratar-se de "um lema que sintetiza uma concepção educacional voltada para a formação da capacidade adaptativa dos indivíduos", num ativismo pragmático que motiva um suspeito fazer autônomo para preservar a ordem social já estabelecida.

Por outro lado, o conceito de práxis em Marx, retomado por Konder (1992, p. 115), enfatiza sua dimensão revolucionária e subversiva, "como atividade concreta pela qual os sujeitos humanos se afirmam no mundo, modificando a realidade objetiva", transformando-se a si mesmos para poderem alterá-la. "É a ação que, para se aprofundar de maneira mais consequente, precisa da reflexão, do autoquestionamento, da teoria; e é a teoria que remete à ação, que enfrenta o desafio de verificar seus acertos e desacertos, cotejando-os com a prática" (KONDER, 1992, p. 115).

A Escola de Frankfurt também retoma a discussão sobre a práxis e a rígida separação que a sociedade contemporânea estabelece, convenientemente, entre teoria e prática, num pensar descolado da vida, da realidade, em um agir isento do compromisso de teorizar, como se as coisas não pudessem ser diferentes do que são (HORKHEIMER, 1983). Adorno (1995) enfatiza que, por mais que critiquemos a razão absoluta, não podemos abandonar o rigor do pensamento, fundamental para uma práxis coerente. Esse mesmo autor, no entanto, nos chama a atenção por sua resistência em fornecer respostas práticas a tudo, negando o imperativo da ação que sufoca o aprofundamento teórico.

Criticando uma perspectiva de fazismo e atuando nessa fissura entre o pensar e o agir, "o ponto de vista crítico é aquele que faz com que o mundo como deveria ser seja parte do mundo como ele é hoje. Por outro lado, é também aquele comportamento que enxerga na

\footnotetext{
${ }^{22}$ Idealizado na década de 1990 por organismos internacionais, no Movimento de Educação para Todos (MEPT), como um pacto entre governo e empresários, com diretrizes do banco mundial para a educação em países em desenvolvimento, pautados nas metas do milênio (FRERES; RABELO; SEGUNDO, 2010).
} 
realidade elementos que impedem a realização dessas potencialidades" (MENEZES BRANDÃO, 2015, p. 142).

Não é possível afirmar que o projeto PAP tenha se efetivado na ausência da criticidade e da consciência de práxis, buscada nos encontros de PAP1 e no processo como um todo, em diversos momentos de formação dos PAP2 e em várias intervenções questionadoras da realidade. $\mathrm{O}$ aprender fazendo, associado à práxis por esse grupo, também é associado (por parte dos coordenadores do projeto) a conceitos da educação ambiental populares na América Latina, os quais pressupõem a participação protagonista do sujeito, na transformação da realidade, na reflexão sobre o que se faz e da possibilidade da aprendizagem em uma prática que não deve ser automatizada.

Entretanto, a disparidade conceitual na literatura entre práxis e aprender fazendo, não explicitada pelos coordenadores do projeto PAP no corpus de dados, revela, por um lado, um deslize da intencionalidade crítica anunciada, que pode ter minimizado o potencial transformador das práxis implicadas pelo projeto. Considerando que toda práxis contempla uma atividade, mas nem toda atividade é uma práxis (KONDER, 1992), a práxis do grupo coordenador se fez atividade irrefletida em alguns aspectos.

Da pesquisa-ação-participante, visualizamos que tais dimensões da pesquisa, da ação e da participação aconteciam ora articuladas, ora desconectadas e parcialmente ausentes. Observamos uma relação desproporcional entre os três aspectos ou, talvez, acontecessem mesmo em momentos diferentes.

Com relação à dimensão da pesquisa, o grupo coordenador encontrou dificuldades para desenvolvê-la durante o projeto. $\mathrm{O}$ excesso de ações influenciava o ritmo da produção científica do grupo, que não tinha tempo e nem fôlego para conduzir pesquisas coletivas mais aprofundadas.

André (2001) nos alerta para a importância de reconhecer as especificidades do campo da pesquisa diante do empirismo. As diferentes etapas de aprofundamento teórico, coleta e análise de dados, que, em geral, são partes de uma pesquisa, demandam uma atenção e, muitas vezes, tempos diferenciados e não simultâneos em relação às praticas educativas.

Destacamos, no entanto, que diversos resumos expandidos (com relatos de experiência) e um livro foram produzidos e divulgados em coautoria entre os PAP1, 2 e 3 no período.

Talvez, a pesquisa esteja subentendida para o grupo PAP1 no fato de se fomentar, pelo projeto, reflexões sobre as ações realizadas. Nesse sentido, o grupo primava por encontros presenciais em que certas questões do planejamento, tomada de decisão e avaliação dos resultados eram trabalhadas e retornavam ao grupo em momentos, intensidades, profundidade e formatos variados, constituindo um percurso reflexivo em espiral ${ }^{23}$. Nesse sentido, as PAP1 Moringa, Capuchinha e Açucena enfatizam seus processos de formação no projeto, afirmando que não estavam restritos aos PAP2, PAP 3 e 4 PAP, mas, ao contrário, ocorriam intensamente a todos os coordenadores, nas relações e reflexões, como pessoas que também aprendem participando (Excerto do Relatório do Projeto Universitário, 2016).

A ação-participante ocorria de forma intensiva no desenvolvimento da capilaridade, dos projetos dos PAP2 e PAP3 na instituição. Entre as ações do projeto, buscou-se problematizar as lacunas existentes; propor/executar algumas possibilidades de soluções no campo da gestão ambiental; desenvolver a reflexão coletiva sobre a prática, mostrando evidências de trabalho colaborativo entre campus universitários, entre faculdades e seus atores. Por vezes, essas intenções resvalavam para o fazismo e o exagero de tarefas.

Por vezes, observavam-se, nesse projeto universitário que se estruturava numa participação em crescimento exponencial, discursos e ações que reproduziam a ideia de formar multiplicadores na instituição. No entanto, tal desvio não passava isento de críticas pela equipe

\footnotetext{
${ }^{23}$ Aspecto discutido em Gatti (2008).
} 
coordenadora - PAP1, que atentava para o risco de perda conceitual e empírica da autonomia e criatividade dos participantes, contido no sentido do termo.

Segundo Tassara e Ardans (2006), a ação, para não escorregar no fazismo, caracterizado por um automatismo imediatista não reflexivo, necessita de um permanente movimento autocrítico individual e coletivo. Na medida em que uma ação-participante fomenta o planejamento, a reflexão sobre as intencionalidades, o aumento do nível de consciência de pessoas e grupos sobre o que se faz poderá colaborar como antítese de um fazismo sempre arriscado a acontecer.

A dimensão da participação, para esses autores, inclui pelo menos dois formatos: "como um meio" para o desenvolvimento de um projeto ou "como um fim em si", como exercício de aprendizagem da "dimensão política democrática" (TASSARA; ARDANS, 2006, p. 62).

Vislumbra-se que tal projeto universitário propiciou participação nesses dois sentidos. Tanto como um meio para ampliar a noção, a discussão e as práticas educadoras e de socioambientalismo na instituição, como no sentido de motivar a participação como um fim, numa instituição que, em geral, não a fomenta em seu modo de funcionar. Nesse sentido, a capilaridade carrega em sua proposta brechas emancipatórias, porque pressupõe um grau de liberdade dos PAP em elaborar seus projetos locais a partir de algumas demandas e desenvolvêlos com protagonismo em seus ambientes de trabalho. O servidor técnico e/ou administrativo estava, oficialmente, com chances de criar, de pensar, de refletir sobre seu trabalho e seus modos de funcionar e desenvolver argumentos, intervenções na realidade. Essa abertura conserva algo incontrolável dentro de uma instituição. $\mathrm{O}$ fomento ao encontro e ao diálogo vem arriscar a reflexão e a ação crítica na universidade muito hierarquizada, colaborando para sua transformação e a implementação de alguns avanços na área.

\section{Algumas considerações}

A análise crítica sobre alguns obstáculos existentes em projetos de formação oferece uma chance de compreender o que impede o potencial emancipatório de se concretizar na prática, perpetuando sem intencionar, semiformação. A estrutura e organização universitárias colocam barreiras burocráticas, hierárquicas, político-econômicas e pedagógicas no desenvolvimento do projeto. Os resultados da pesquisa apontam reflexões sobre certa incoerência e cisão internas nesse lócus da produção de conhecimentos, devido a resistências a transformações e melhorias - a aprender com o que faz, com dificuldades de internalizar suas produções e descobertas no campo da EA e da sustentabilidade.

A própria práxis do grupo coordenador do projeto aqui investigado também oscila entre criticidade e adaptação à realidade institucional. O eixo teórico-metodológico de pesquisa-açãoparticipante do processo de formação, recorrentemente traduzido em pessoas que aprendem participando e aprender fazendo, expõe visões e práxis contraditórias em que o aprenderfazendo se revela como uma práxis em relação com ações transformadoras, educação popular e reflexão crítica, ao mesmo tempo em que oscila, no referido projeto, um ativismo pragmático.

Cabe ressaltar que os objetivos traçados e os esforços desse coletivo, do órgão ambiental e seus parceiros comprometidos em democratizar a formação socioambiental dentro da IES, em uma arquitetura de capilaridade, representam relevante iniciativa e um exemplo de resistência aos treinamentos e manuais frequentemente adotados na formação do quadro de técnicos de grandes organizações. Nesse sentido, está o aprender a participar - como meio e fim - numa sociedade e instituição que, em geral, anestesiam tais motivações. De forma geral, a educação ambiental em capilaridade estudada apontou para a potencialização da autonomia e da liberdade na instituição. Mesmo diante de suas contradições, conservam lampejos de emancipação, antítese de semiformação. 
As universidades, como lócus tradicionais de reflexões e produção de conhecimentos, pesquisa, ensino e extensão, possuem uma responsabilidade social diferenciada na busca por subsidiar a sociedade em teorias, reflexões críticas, pesquisas, inovações e experiências de Educação Ambiental e sustentabilidade. Entendemos que a universidade deve exercitar a sustentabilidade e buscar sua própria mudança valorizando a sua produção científica de forma a enraizá-la em seu próprio modo de funcionar. Permanece o desafio de manter e aprofundar reflexões e ações críticas, como resistência à semiformação nos processos de educação ambiental em universidades.

\section{Referências}

ADORNO, T. L. W. Educação e emancipação. 3 ed. Rio de Janeiro: Paz e Terra, 1995.

ADORNO, T. L. W. A dialética negativa. Rio de Janeiro: Zahar, 1996.

ADORNO, T. L. W Teoria da semiformação. In: PUCCI, B.; ZUIN, A. A. S., et al (Eds.). Teoria crítica e inconformismo: novas perspectivas de pesquisa. Campinas: Autores Associados, 2010. p.7-40.

ADORNO, T. L. W.; HORKHEIMER, M. A industria cultural: o esclarecimento como mistificação das massas. In: ADORNO, Theodor W.; HORKHEIMER, Max. Dialética do esclarecimento: fragmentos filosóficos. 2 ed. Rio de Janeiro: ZAHAR, 1985, p.113-156.

ADORNO, T. L. W.; HORKHEIMER, M. Dialética do esclarecimento. Rio de Janeiro: Zahar, 1985.

ANDRÉ, M. Pesquisa em educação: buscando rigor e qualidade. Cadernos de Pesquisa, São Paulo. n.113, p. 51-64, jul., 2001. Disponível em:

<http://www.scielo.br/scielo.php?script=sci_arttext\&pid=S0100-15742001000200003\&nrm=iso>. Acesso em: 10 de abril de 2014.

BACCI, D. L. C.; SILVA, R. L. F.; SORRENTINO, M. Educação ambiental e universidade: diagnóstico disciplinar para a construção de uma política ambiental. In: ENCONTRO PESQUISA EM EDUCAÇÃO AMBIENTAL, 8, 2015, [s.n.] Rio de Janeiro: UFRJ, U.; UNIRIO; Anais eletrônico [...], 2015. Disponível em: <http://epea.tmp.br/epea2015_anais/plenary/>. Acesso em: 15 abr. 2016.

BRANDLI, L. L. et al. The Environmental Sustainability of Brazilian Universities: Barriers and Preconditions | SpringerLink. In: FILHO, W. L.;AZEITEIRO, U. M., et al (Eds.). Integrating sustainability thinking in science and Engineering curricula. Switzerland: Springer International Publishing, 2015. p.63-74.

BRANDÃO, C. R. Participar-pesquisar. In: BRANDÃO, Carlos Rodrigues (Org.). Repensando a pesquisa participante. 3 ed. São Paulo: Brasiliense, 1987. p. 7-14.

BRANDÃO, C. R.; STRECK, D. R. A pesquisa participante e a participação da pesquisa: um olhar entre tempos e espaços a partir da América Latina (Participatory research and participation in research: a look between times and spaces from Latin America). In: ; (Eds.). Pesquisa participante: a partilha do saber (Participating research: the sharing os knowledge). Aparecida: Ideias \& Letras, 2006.p. 21-54.

BRASIL. M. M. A.; EDUCAÇÃO, M. Programa Nacional de Formação de Educadoras (es) Ambientais. Brasília: Secretaria Executiva: 2003/2006. 
CÂMARA DOS DEPUTADOS. Conferência das Nações Unidas sobre o Meio Ambiente e Desenvolvimento (1992: Rio de Janeiro). Conferência das Nações Unidas sobre o Meio Ambiente e Desenvolvimento: de acordo com a Resolução: JP 44/228 da Assembléia Geral da ONU, de 22-12-89, estabelece uma abordagem equilibrada e integrada das questões relativas a meio ambiente e desenvolvimento: a Agenda 21 - Brasília: Câmara dos Deputados, Coordenação de Publicações, 1995. disponivel em: 〈http://bd.camara.gov.br/bd/handle/bdcamara/7706?show=full〉.

CARVALHO, I. C. M. Em direção ao mundo da vida: interdisciplinaridade e educação ambiental / Conceitos para se fazer educação ambiental. Brasília: Instituto de Pesquisas Ecológicas (IPE), 1998.

CARVALHO, I. C. M. Qual a educação ambiental? Elementos para um debate sobre educação ambiental e extensão rural. Agroecologia e Desenvolvimento Rural Sustentável. Porto Alegre: Red Scielo. 2: 43-51 p. 2001.

CARVALHO, I. C. M.; FARIAS, C. R. O. Um balanço da produção científica em educação ambiental de 2001 a 2009 (ANPEd, ANPPAS e EPEA). Revista Brasileira de Educação, São Paulo, v. 16, n.46, p. 119-134, jan-abr., 2011. Disponível em:

<http://www.scielo.br/scielo.php?script=sci_arttext\&pid=S1413-24782011000100007\&nrm=iso >. Acesso em: 10 de maio de 2014.

CARVALHO, I. C. M.; SILVA, R. S. Ambientalização no ensino superior e experiência da Pontifícia Universidade Católica do Rio Grande do Sul. In: RUSCHEINSKY, A. (Ed.). Ambientalização nas instituições de educação superior no Brasil: caminhos trilhados, desafios e possibilidades. São Carlos: EESC/USP, 2014. p.125-144.

CARVALHO, L. M. ; TOMAZELLO, M. G. C.; OLIVEIRA, H. T. Pesquisa em educação ambiental: panorama da produção brasileira e alguns de seus dilemas. Cadernos CEDES, Campinas, v. 29, n., p. 13-27, jan.-abr., 2009. Disponível em:

<http://www.scielo.br/scielo.php?script=sci_arttext\&pid=S0101-32622009000100002\&nrm=iso >. Acesso em: 15 de maio de 2014.

DELORS, J.; AL, E. Educação, um tesouro a descobrir: relatório para a UNESCO da Comissão Internacional sobre Educação para o século XXI (1996). Tradução: Reinaldo de Lima Reis. Brasília Setor de Educação da Representação da UNESCO no Brasil, 2010. 43p.

DISTERHEFT, A. et al. Participatory processes in sustainable universities - what to assess?

International Journal of Sustainability in Higher Education, Bingley, United Kingdom, v. 16, n. 5, p. 748-771, set., 2015. Disponível em: <https://www.emeraldinsight.com/doi/abs/10.1108/IJSHE-052014-0079 >. Acesso em: 05 de outubro de 2016.

DUARTE, N. As pedagogias do "aprender a aprender" e algumas ilusões da assim chamada sociedade do conhecimento. Revista Brasileira de Educação, São Paulo, n.18, p. 35-40, set-dez. 2001. ISSN 1413-2478. Disponível em: <http://www.scielo.br/scielo.php?script=sci_arttext\&pid=S1413-

24782001000300004\&nrm=iso >. Acesso em: 17 de abril de 2016.

FARIA, J. H.; MENEGHETTI, F. K. Dialética negativa e a tradição epistemológica nos estudos organizacionais. Organizações \& Sociedade, Salvador, v. 18, n.56, p. 119-137, jan-març., 2011. Disponível em: < http://www.scielo.br/scielo.php?script=sci_arttext\&pid=S198492302011000100006\&nrm=iso >. Acesso em: 20 de agosto de 2013.

FERRARO JUNIOR, L. A. Incorporação da questão ambiental na universidade vista a partir de dentro da gestão ambiental do Estado. In: RUSCHEINSKY, Aloisio; GUERRA, Antonio Fernando S; 
FIGUEIREDO, Mara Lúcia; et al. Ambientalização nas instituições de educação superior no Brasil: caminhos trilhados, desafios e possibilidades. São Carlos: Plural Ltda., 2014. p. 262-279.

FERRARO JUNIOR, L. A.; SORRENTINO, M. Coletivos educadores. In: AMBIENTE, M. D. M. (Ed.). Formação de educadoras/es ambientais e coletivos educadores. Brasília-DF: MMA, Diretoria de Educação Ambiental, v.1, 2005. p. 57-69.

FRERES, H.; RABELO, J. J.; SEGUNDO, M. D. M. Governo e empresariado: a grande aliança em prol do mercado da educação para todos. In: JIMENEZ, S.; RABELO, J. J., et al (Eds.). Marxismo, educação e luta de classes: pressupostos ontológicos e desdobramentos ideo-políticos. Fortaleza: EduEce, 2010. p.33-59.

GAJARDO, M. Pesquisa participante: propostas e projetos. In: BRANDÃO, C. R. (Ed.). Repensando a pesquisa participante. 3 ed. São Paulo: Brasiliense, 1987. p.15-50.

GATTI, B. A. Pesquisa em ação: produção de conhecimento e produção de sentidos como desafio. In: SEMINÁRIO DE PESQUISA E PÓS-GRADUAÇÃO, 2008, São Leopoldo: Fundação Carlos Chagas. Anais Unisinos... São Leopoldo: UNISINOS, 2008. p. 1-15.

GONZÁLEZ-GAUDIANO, E. Otra lectura a la historia de la edicación ambiental en América Latina y el Caribe. Desenvolvimento e Meio Ambiente, Curitiba-PR, n.3, p. 141-158, jan-junh. 2001.

Disponível em: < https://revistas.ufpr.br/made/article/view/3034/2425 >. Acesso em: 10 de outubro de 2014.

GOERGEN, P. Teoria e ação no GT Educação Ambiental da ANPED: partilhando algumas suspeitas epistemológicas. Pesquisa em Educação Ambiental, Rio Claro, v. 5, n. 2, p. 9-30, jul. 2010. Disponível em: < http://www.periodicos.rc.biblioteca.unesp.br/index.php/pesquisa/article/view/6211 $>$. Acesso em: 04 de fevereiro de 2014.

GOERGEN, P. A ética e o futuro da humanidade: considerações críticas sobre educação ambiental. Pesquisa em Educação Ambiental, Rio Claro, v. 9, n.1, p. 10-23, jan-junh. 2014. Disponível em: < http://ojs-teste.biblioteca.unesp.br/index.php/pesquisa/article/view/8836/6162 >. Acesso em: 16 de abril de 2015

GONDIM, S. M. G. Grupos focais como técnica de investigação qualitativa: desafios metodológicos. Paidéia, Ribeirão Preto, v. 12, n.24, p. 149-161, 2003. Disponível em:

$<$ http://www.scielo.br/scielo.php?script=sci_arttext\&pid=S0103-863X2002000300004 >. Acesso em: 12 de março de 2013.

GRUSCHKA, A. Frieza burguesa e educação: a frieza como mal-estar moral da cultura burguesa na educação. Campina: Autores associados, 2014.

HORKHEIMER, M.; ADORNO, T. W. Temas básicos da sociologia. São Paulo: Cultrix, 1973.

HORKHEIMER, M. Teoria tradicional e Teoria crítica. In: HORKHEIMER, M.; ADORNO, T. W. (Eds.). Textos escolhidos. São Paulo: Abril Cultural, 1983. p. 31-68.

KIND, L. Notas para o trabalho com a técnica de grupos focais. Psicologia em Revista, Belo Horizonte, v. 10, n.15, p.124-136,junh. 2004.

KONDER, L. A filosofia da Práxis. In: (Ed.). O futuro da filosofia da práxis: o pensamento de Marx no século XXI. Rio de Janeiro: Paz e Terra, 1992. p.96-128. 
LAYRARGUES, P. P.; LIMA, G. F. C. Mapeando as macrotendências político-pedagógicas da educação ambiental contemporânea no Brasil. In: ENCONTRO PESQUISA EM EDUCAÇÃO AMBIENTAL, set. 2011, Ribeirão Preto. Anais[...] Ribeirão Preto: Universidade de São Paulo, 2011. p. 1-15. Acessível em: <http://www.icmbio.gov.br/educacaoambiental/images/stories/biblioteca/educacao_ambiental/Layrarg ues_e_Lima_-_Mapeando_as_macro-tend\%C3\%83\%C2\%AAncias_da_EA.pdf $>$.

LIMA, G. F. C. Crise ambiental, educação e cidadania: os desafios da sustentabilidade emancipatória. In: LAYRARGUES, P. P.;CASTRO, R. S. D. (Eds.). Educação ambiental: repensando o espaço da cidadania. São Paulo: Cortez, 2002. p.109-141.

LOUREIRO, C. F. B. Emancipação e complexidade: para o repensar das tendências em educação ambiental. In: MINISTÉRIO DO MEIO AMBIENTE. Encontros e Caminhos: formação de educadoras (es) ambientais e coletivos educadores. Brasília: Ministério do Meio Ambiente, v.2, 2007. p.157-170.

LOUREIRO, C. F. B. et al. Contribuições da teoria marxista para a educação ambiental crítica. Cadernos CEDES, Campinas, v. 29, n.77, p. 81-97, jan-abr., 2009. Disponível em: $<$ http://www.scielo.br/scielo.php?script=sci_arttext\&pid=S0101-32622009000100006\&nrm=iso >. Acesso em: 16 de març de 2015.

MENEZES BRANDÃO, F. A escola de Frankfurt como ponto de inflexão entre a crítica e a práxis social. Cadernos de Educação, Tecnologia e Sociedade (CETS), Inhumas, v.8, n.2, p. 139-147, set. 2015. Disponível em: https://www.researchgate.net/publication/282517275.

MORAES, R. Uma tempestade de luz: a compreensão possibilitada pela análise textual discursiva. Ciência \& Educação, Bauru, v. 9, n.2, p. 191-211, out. 2003. Disponível em: http://www.scielo.br/scielo.php?script=sci_arttext\&pid=S1516$73132003000200004 \& \operatorname{lng}=e n \& n r m=$ iso. Acesso em: 13 de dezembro de 2013.

MORAES, R.; GALIAZZI, M. C. Análise textual discursiva: processo reconstrutivo de múltiplas faces. Ciência \& Educação, Bauru, v. 12, n.1, p. 117-128, jan/abr 2006. Disponível em: $<$ http://www.scielo.br/scielo.php?script=sci_arttext\&pid=S1516-73132006000100009\&nrm=iso >. Acesso em: 11 de julho de 2013.

OLIVEIRA, H. T.; FREITAS, D. Ambientalização nos cursos de licenciatura por meio da inclusão curricular de uma disciplina: o caso da USFCar (Brasil). In: GELI, A. M.; PAVESI, A., et al (EdS.). Ambientalização da educação superior como aprendizagem institucional. São Carlos: Universidade Federal de São Carlos, 2004, v. 49, p. 155-172.

OLIVEIRA, H. T. et al. Mapeamento da Educação Ambiental em Instituições Brasileiras de Educação Superior: elementos para políticas públicas. Brasília: MEC/MMA/RUPEA, 2007.

PUCCI, B. O caráter assistemático dos escritos de Adorno. Comunicações, Piracicaba, v.5, n. 2, p.40-48, 1998.

PUCCI, B. Considerações extemporâneas acerca das metodologias qualitativas. Comunicações, Piracicaba, v.7, n. 1, p.255-259, 2000.

ROCHA, E. E. R. B. A pesquisa participante e seus desdobramentos: experiências em organizações populares. In: CONGRESSO BRASILEIRO DE EXTENSÃO UNIVERSITÁRIA, 12-15 de set., 2004, Belo Horizonte, MG. Anais[..]. Maringá: Universidade Estadual de Maringá, 2, 2004. p. [sn]. Disponível em: <https://www.ufmg.br/congrext/Direitos/Direitos8.pdf>. 
SJÖSTRÖM, J.; EILKS, I.; ZUIN, V. Towards Eco-Reflexive Science Education: A critical reflection about educational implications of green chemistry. Science \& Education, Malmo, Sweden, v. 25, n. 3-4, p. 321-341, mar. 2016.

SORRENTINO, M.; BIASOLI, S. A. A educação ambiental contribuindo para a construção de sociedades sustentáveis. In: RUSCHEINSKY, Aloisio; GUERRA, Antonio Fernando S; FIGUEIREDO, Mara Lúcia; et al. Ambientalização nas instituições de educação superior no Brasil: caminhos trilhados, desafios e possibilidades. São Carlos: Plural Ltda., 2014. p. 39-46.

SOUZA, S. C.; LOGAREZZI, A. J. M. O exercício da liberdade na ética tradicional ribeirinha pantaneira amparado na dialogicidade e na criticidade: reflexões teóricas. Pesquisa em Educação Ambiental, Rio Claro, v. 13, n.2, p. 101-116, julh.-dez.2018. Disponível em:

$<$ https://www.periodicos.rc.biblioteca.unesp.br/index.php/pesquisa/article/view/13104/8772 >. Acesso em: 10 de janeiro de 2019.

SUDAN, D. C. Educação Ambiental e Teoria Crítica: a Dialética da Emancipação na Formação Socioambiental de servidores de uma universidade pública do estado de São Paulo. 2017. 265 f. Tese (Doutorado em Educação) - Programa de Pós-Graduação Em Educação/PPGE, Universidade Federal de São Carlos, São Carlos, 2017.

SUDAN, D. C.; ZUIN, V. G. La emancipación en educación ambiental: formación en una Universidad Brasileña. Multidisciplinary Journal of Education Research, Barcelona, Spain, v. 8, n.2, p. 205230, junh.-out., 2018a. Disponível em:

<http://hipatiapress.com/hpjournals/index.php/remie/article/view/3203 >. Acesso em: 15 de outubro de 2018. doi: 10.17583/remie.2018.3203

SUDAN, D. C.; ZUIN, V. G. Emancipation in environmental education for the non-teaching staff: a brazilian higher education case study. Building bridges across disciplines for transformative education and a sustainable future. In: A collection of invited papers inspired by the $24^{\text {th }}$ SYMPOSIUM ON CHEMISTRY AND SCIENCE EDUCATION. June, 1-3, 2018. EIKS, I.; MARKIC, S.; RALLE, B. (Eds.), 24, 2018, Bremen. Proceedings... Aachen: Shaker Verlag, 2018b. p. 275-281. ISBN. 978-38440-6255-7

TASSARA, E. T. O.; TASSARA, H.; ARDANS, H. O. Empoderamento (versus empoderar-se). In: JUNIOR, L. A. F. (Ed.). Encontros e caminhos: formação de educadoras(es) ambientais e coletivos educadores, Brasília: MMA/DEA, v.3, 2013. p. 59-71.

TASSARA, E. T. O.; ARDANS, H. O. Educação Ambiental Crítica: pesquisa-ação, participação, silêncios e "silenciamentos". Pesquisa em Educação Ambiental, São Paulo, v. 1, n.1, p. 59-71, julhdez., 2006.

TONSO, S. A educação ambiental que desejamos desde um olhar para nós mesmos. Ciência em Foco. Campinas, v. 1, n. 3 p. 1-15, jan., 2010.

TRATADO DE EDUCAÇÃO AMBIENTAL PARA SOCIEDADES SUSTENTÁVEIS E RESPONSABILIDADE GLOBAL, ECO-92, Rio de Janeiro, Brasil, 1992. In: BRASIL. Ministério do Meio Ambiente. Disponível em: < http://www.mma.gov.br/port/sdi/ea/deds/pdfs/trat_ea.pdf >.

TÜRCKE, C. Substituto da sensação. In: . (Ed.). Sociedade excitada: filosofia da sensação. Campinas: Editora da Unicamp, 2010. p.233-319.

VIZEU, F.; MENEGHETTI, F. K.; SEIFERT, R. E. Por uma crítica ao conceito de desenvolvimento sustentável. Cadernos Ebape, Rio de Janeiro, v. 10, n.3, p. 569-583, set., 2012. Disponível em: < 
http://www.scielo.br/scielo.php?script=sci_arttext\&pid=S1679-39512012000300007\&nrm=iso >. Acesso em: 15 de março de 2013.

ZERBINI, F. M. Emancipação e ambientalismo: um estudo sobre fundamentos para uma educação ambiental crítica. Ano de depósito:2008. 181f. Tese (Doutorado em Ciência Ambiental) Universidade de São Paulo, São Paulo, 2011.

ZUIN, V. G. A inserção da dimensão ambiental na formação inicial de professoras/es de química: um estudo de caso. 2010, 253p. Tese (Doutorado em Educação / área de concentração Ensino de Ciências e Matemática) - Departamento de Educação, Universidade de São Paulo, São Paulo, 2010.

. Tecnologia, cultura e educação em perspectiva interdisciplinar para o enfrentamento dos desafios contemporâneos. In: PHILIPPI JUNIOR, A.; FERNANDES, V. (Orgs.). Práticas da interdisciplinaridade no ensino e pesquisa. Barueri: Manole, 2015. p. 449-469.

ZUIN, V. G.; ZUIN, A. A. S. A industria cultural e insustentabilidade dos rótulos verdes. In: ZUIN, A. A. S.; LASTORIA, L. A. C. N.; GOMES, L. R. (Org.). Teoria crítica e formação cultural: aspectos filosóficos e sócio-políticos. 1 ed. Campinas: Autores Associados, 2012. p. 105-123.

ZUIN, V. G.; ZUIN, A. A. S. A formação no tempo e no espaço da internet e das coisas. Educação \& Sociedade, São Paulo, v. 37, n., p. 757-773, julh-set., 2016. Disponível em: $<$ http://www.scielo.br/scielo.php?script=sci_arttext\&pid=S0101-73302016000300757\&nrm=iso >. Acesso em: 14 de julh., 2017.

ZUIN, V. G.; ZUIN, A. A. S. A atualidade do conceito de semiformação e o renascimento da Bildung. Revista Espaço Pedagógico, Passo Fundo, v.24, n.3, p. 420-436, 19 dez., 2017. 